\title{
Sex, price and preferences: accounting for unsafe sexual practices in prostitution markets Stef Adriaenssens and Jef Hendrickx
}

\author{
Hogeschool-Universiteit Brussel, Belgium
}

\begin{abstract}
Unsafe sexual practices are persistent in prostitution interactions: one in four contacts can be called unsafe. The determinants of this are still matter for debate. We account for the roles played by clients' preferences and the hypothetical price premium of unsafe sexual practices with the help of a large dataset of clients' self-reported commercial sexual transactions in Belgium and The Netherlands. Almost 25,000 reports were collected, representing the whole gamut of prostitution market segments. The first set of explanations consists of an analysis of the price-fixing elements of paid sex. With the help of the so-called hedonic pricing method we test for the existence of a price incentive for unsafe sex. In accordance with the results from studies in some prostitution markets in the developing world, the study replicates a significant wage penalty for condom use of an estimated 7.2 per cent, confirmed in both multilevel and fixed-effects regressions. The second part of the analysis reconstructs the demand side basis of this wage penalty: the consistent preference of clients of prostitution for unsafe sex. This study is the first to document empirically clients' preference for intercourse without a condom, with the help of a multilevel ordinal regression.
\end{abstract}

Keywords: prostitution, sex work, unsafe sex, condom use, compensating differentials, client

\section{Problem}

Risk and safety are inextricably bound to the social phenomenon called prostitution. ${ }^{1}$ Prostitution is the continual supply of physical sexual intercourse of some kind in direct exchange for material rewards, usually money. No one doubts the fact that prostitution risks harming the quality of life of the parties involved. Sex workers, for example, have lower scores on self-esteem and environmental health (Holroyd et al. 2008, Wong et al. 2006). In this article we focus on health aspects and, more particularly, on the behaviour that significantly increases the parties' risk of being infected with a sexually transmitted disease (STD).

This contribution narrows this idea of high risks down to the two parties that are directly involved, clients and sex workers. The study is also limited to heterosexual prostitution. This implies in practice that it is confined to those situations where men purchase sexual services either from women or from transgender sex workers presenting themselves as women.

(c) 2011 The Authors. Sociology of Health \& Illness (c) 2011 Foundation for the Sociology of Health \& Illness/Blackwell Publishing Ltd. Published by Blackwell Publishing Ltd., 9600 Garsington Road, Oxford OX4 2DQ, UK and 350 Main Street, Malden, MA 02148, USA 


\section{Stef Adriaenssens and Jef Hendrickx}

From a perspective of occupational wellbeing, it is safe to state that the strains and risks involved in sex work are manifold and are higher than in many other occupations (Sanders 2004). The risks of being harassed or even physically assaulted are high (Murphy and Venkatesh 2006, Simić and Rhodes 2009). Recent research concludes that one-third of the Israeli sex workers interviewed reported sexual or physical assaults (Cwikel et al. 2003). Farley et al's survey (1998) in five countries indicates that half of the sex workers were raped in prostitution. Elsewhere, the self-reported prevalence of physical assault is consistently high (in particular Raphael and Shapiro, 2004), somewhere between one-third and two-thirds of the respondents. The risks of being victimised in violent crime may be rather one-sided with the prostitutes as the main victims, but due to poor documentation hard evidence on clients and bystanders is lacking.

The hazards that are related to sex work tend to affect more people than those directly involved in the interactions. Negative externalities are exemplified by the alleged rise in crime and public nuisance associated with certain forms of prostitution (Hubbard 2004, Kantola and Squires 2004). In the area of public health, prostitution may play a decisive factor in the spread of STDs to third parties. One should not reduce adverse health effects in prostitution to STDs, however (Chacham et al. 2007, Cusick 2006). Violence, psychosocial stress and workload may also have serious health effects. That being said, STDs are without doubt a significant part of the health risks of paid sex. Also they tend to have strong feedback on other negative work outcomes.

Therefore we argue that STDs threaten people's quality of life both directly and indirectly. Moreover, the high costs of treatment imply a burden to healthcare expenses (Korn 2008). Poor health and high expenses also affect this group's quality of life through socioeconomic and direct wellbeing effects.

We start from the intuition that effective policies need empirically informed assessments of the behaviour of the parties and the reasons and motivations for this behaviour. It is not easy, however, to collect reliable data about prostitution. The data for our analyses consist of reviews posted on the internet by prostitution clients in Belgium and The Netherlands. The obvious advantage is that they provide a wealth of first-hand reports about an activity normally hidden in the informal and underground economies and burdened with stigma and shame. Thanks to the voluntary nature of the reviews, the guarantee of anonymity and the frequency of reviews, an acceptable picture of what is going on in mainstream prostitution markets can be assumed.

This article first of all makes a contribution to the work in progress aiming to make sense of unsafe sexual behaviour in prostitution. Therefore we start from earlier estimates of price incentives to engage in unsafe sex. These estimates, based on the hedonic pricing method, provide consistent evidence that the price of sexual transactions rationalises unsafe sexual practices. However, reasons other than price exist. All the motivations assume a preference for unprotected intercourse on the demand side. Therefore, it is a useful exercise to go from revealed preferences as they are manifested in the price to direct measures of preference. It so happens that the logic behind price or other incentives that make (some) sex workers yield to unsafe practices is the preference of a proportion of the clients for unprotected sex. This contribution is the first to test empirically this dominant preference for unprotected sex on the part of male clients.

The following section introduces the data and assesses their strengths and weaknesses. The third section discusses our measurement of unsafe sexual practices and presents a first exploration of the data. The persistence of unsafe sexual behaviour is explained in the fourth and fifth sections. The fourth section replicates earlier studies that explained unsafe practices in commercial sex with the help of the hedonic pricing method. Because price incentives do 
not embrace all possible motivations for unsafe sexual practices, we measure the preference for unsafe sexual intercourse directly in the fifth section.

\section{Data and method}

The emergence of the internet has profoundly changed the experiences of commercial sex (Döring 2009, Quinn and Forsyth 2005). At the same time it provides prostitution researchers with novel opportunities for collecting and analysing data.

Most countries have websites with user-generated content at the disposal of clients. These message boards enable clients to share information about experiences. Some websites attract a diverse and active public providing a reasonable image of the (mainstream) prostitution market. In the Low Countries, the user-generated website of http://www.hookers.nl ${ }^{2}$ (Hookers n.d.) attracts attention for several reasons: it has a dominant position, the messages are hardly ever censored and it is possible to post messages both in a standardised and in an open way. We discuss these arguments in favour of this site in some detail.

First of all, hookers.nl has the appropriate structure for a quantitative analysis. Not only does it cover a rather long period (since the end of 2002); more important is the fact that clients have the opportunity not only to report their experiences in an open way, but also to fill out a standardised questionnaire to review their experience. The procedure is as follows. Any visitor can visit the basic information of the website. Whoever wishes to add content or consult the standardised reviews needs to register (for free) with an alias, without giving his name or other personal information.

Other message boards in the Low Countries exist but they do not offer the possibility of filling out a standardised questionnaire. The same lack of standardised sources seems to dominate the research literature, as we found only one example of quantitative research (Moffatt and Peters 2004), while quite a few interesting qualitative investigations have been published (for example, Blevins and Holt 2009, Soothill and Sanders 2005).

Secondly, the site is organised in such a way and attracts enough clients and interactions to allow for data of sufficient quality and representativeness to be harvested. Therefore, the overall reliability of the reported characteristics of sex workers and their services is rather high. Every group on the site organised as one type of prostitution in one city or area is run by an administrator who checks every review. The administrators decide on the features of the sex worker (working area, age, physical appearance), often after a discussion with several clients. They also remove reviews that are obviously misinformed, posted for commercial reasons or in cases of 'flaming' (slandering on the internet). Reviewers persisting in this kind of behaviour are also banned. Furthermore, the ethical code on sexual behaviour is much less rigid than in most other sites. The extent of control by the administrators is thus limited to the discussion of the appropriate discussion board and to the removal of intentional misinformation. For our research purposes it is the open way of reporting unprotected sexual intercourse that is important. Most sites censure reviews of unprotected sex. For example Punternet, the well-known British counterpart of Hookers, rejects every review that 'mentions unprotected vaginal or anal intercourse' (Punternet n.d.). Hookers.nl, on the other hand explicitly records whether the intercourse took place with or without a condom.

In short, we argue that the user-generated content, and in particular the standardised reviews that are available on hookers.nl, are reasonably representative of interactions on the mainstream heterosexual prostitution markets in the Low Countries. Some niches are not represented at all (for example, illegal prostitution with minors) and others probably are underrepresented (for example, some smaller ethnic prostitution markets). But overall, we 
assume that the reviews constitute a representative sample of the interactions in the main types of female prostitution in both countries (see summary statistics in Table 1). All the standardised reviews from the website were collected in the spring and summer of 2009.

The data also provide detailed information about the services provided during the transaction. Clients can indicate which of 31 services they have enjoyed, ranging from fellatio and vaginal penetration that take place most often to less frequent services such as anal penetration. A final advantage of the data is that multiple reviews about the same sex worker are identified as such. The distinction between the supplier of a service and the exchange provides major analytical advantages enabling us to distinguish between sex worker and the service as different levels. In Table 2 the main data that were used in the forthcoming regression analyses are concisely explained. We show the way they were filled out in the review form and how these data were recoded into variables.

\section{Unsafe interaction in commercial sex}

Health in prostitution is strongly associated with unsafe sexual practices. As argued before, unsafe sexual practices are a privileged hazard for the quality of life of prostitutes and clients but they are certainly not the only factor that adversely affects quality of life in general or health in particular.

What is unsafe is a matter of discussion: it still is difficult to untangle the role of behaviour in the spread of STDs (Aral 2004). However, for our purposes enough agreement exists for us to distinguish between reasonably safe and unsafe practices. We consider interactions to be unsafe when they have a significantly higher risk of leading to an infection with a STD, with adverse consequences for the quality of life of the person infected.

The discussion about the most effective and efficient prophylaxis is seriously limited in this research, as the causal field of prostitution precludes discussions about conceivable interventions such as abstinence or monogamy. The risk of transmission of STDs in

Table 1 Summary statistics

\begin{tabular}{|c|c|c|c|c|c|c|c|}
\hline & \multicolumn{2}{|c|}{$\begin{array}{l}\text { Sex } \\
\text { workers }(N)\end{array}$} & \multicolumn{2}{|c|}{ Interactions $(N)$} & \multicolumn{3}{|c|}{$\begin{array}{l}\text { Unsafe sexual practices } \\
\text { (\% of interactions) }\end{array}$} \\
\hline & $N L$ & $B E$ & $N L$ & $B E$ & $N L$ & $B E$ & Total \\
\hline Vaginal penetration & 4908 & 1518 & 15439 & 4092 & 2.11 & 1.12 & 1.90 \\
\hline Anal penetration & 470 & 117 & 990 & 302 & 10.7 & 8.6 & 10.2 \\
\hline Fellatio & 4842 & 1499 & 15776 & 4066 & 26.9 & 40.4 & 29.6 \\
\hline All three practices & 5551 & 1900 & 19584 & 5414 & 22.0 & 30.8 & 23.9 \\
\hline $\begin{array}{l}\text { Windows and street } \\
\text { prostitution }\end{array}$ & 2520 & 657 & 10088 & 2353 & 10.8 & 6.3 & 10.0 \\
\hline Clubs and private & 1135 & 286 & 3632 & 653 & 32.5 & 49.3 & 35.1 \\
\hline Escort and private & 1439 & 507 & 3833 & 1450 & 45.4 & 58.7 & 49.0 \\
\hline $\begin{array}{l}\text { Specialties: BDSM, } \\
\text { gangbangs and } \\
\text { transsexuals }\end{array}$ & 457 & 450 & 2031 & 958 & 14.8 & 35.9 & 21.5 \\
\hline Total & 5551 & 1900 & 19584 & 5414 & 22.0 & 30.8 & 23.9 \\
\hline
\end{tabular}

Note: BDSM, bondage and discipline, dominance and submission; BE, Belgium; NL, The Netherlands.

(C) 2011 The Authors

Sociology of Health \& Illness (C) 2011 Foundation for the Sociology of Health \& Illness/Blackwell Publishing Ltd 
Table 2 Description of variables

\begin{tabular}{|c|c|c|}
\hline $\begin{array}{l}\text { Variables used in the } \\
\text { regression model }\end{array}$ & Explanation & $\begin{array}{l}\text { Based on the following topics in } \\
\text { the standardised questionnaire }\end{array}$ \\
\hline Price $(\ln )$ & Natural logarithm of the price & $\begin{array}{l}\text { Price paid to the prostitute } \\
\text { in euros }\end{array}$ \\
\hline Unsafe sexual practice & $\begin{array}{l}\text { A dummy variable that indicates } \\
\text { whether at least one of the } \\
\text { following services took place } \\
\text { without a protective sheath: } \\
\text { vaginal penetration, anal } \\
\text { penetration or fellatio }\end{array}$ & $\begin{array}{l}\text { Based on the following items: } \\
\text { vaginal penetration with or } \\
\text { without condom } \\
\text { anal penetration with or without } \\
\text { condom } \\
\text { fellatio with or without } \\
\text { protection }\end{array}$ \\
\hline Duration $(\ln )$ & $\begin{array}{l}\text { Natural logarithm of the } \\
\text { duration of the interaction }\end{array}$ & $\begin{array}{l}\text { Duration in minutes } \\
\text { (5 minute intervals) }\end{array}$ \\
\hline Age & Age of the prostitute & $\begin{array}{l}\text { Age in years (in intervals of } \\
3 \text { years) }\end{array}$ \\
\hline Thin & $\begin{array}{l}\text { Dummy variable that indicates } \\
\text { whether the prostitute is } \\
\text { considered to be thin }\end{array}$ & $\begin{array}{l}\text { Based on the ordinal variable } \\
\text { 'shape' in the questionnaire with } \\
\text { the categories thin, slim, } \\
\text { normal, corpulent or fat }\end{array}$ \\
\hline Obese & $\begin{array}{l}\text { Dummy variable that indicates } \\
\text { whether the prostitute is } \\
\text { considered corpulent or fat }\end{array}$ & $\begin{array}{l}\text { Based on the ordinal variable } \\
\text { 'shape' (see variable 'thin') }\end{array}$ \\
\hline Appearance rating & $\begin{array}{l}\text { Appearance of the prostitute on } \\
\text { a scale from } 1 \text { to } 5\end{array}$ & $\begin{array}{l}\text { Ordinal variable 'appearance' } \\
\text { with categories 1: poor, 2: } \\
\text { mediocre, 3: sufficient, 4: } \\
\text { good, 5: excellent }\end{array}$ \\
\hline Hygiene rating & $\begin{array}{l}\text { Hygiene of the prostitute on } \\
\text { a scale from } 1 \text { to } 5\end{array}$ & $\begin{array}{l}\text { Ordinal variable 'hygiene' with } \\
\text { same categories as appearance }\end{array}$ \\
\hline Anal (prostitute) & Dummy variable & $\begin{array}{l}\text { Anal intercourse with prostitute? } \\
\text { (yes, no) }\end{array}$ \\
\hline Anal (client) & Dummy variable & $\begin{array}{l}\text { Anal intercourse with client? } \\
\text { (yes, no) }\end{array}$ \\
\hline SM & Dummy variable & SM service? (yes, no) \\
\hline Total of extra services & $\begin{array}{l}\text { Total of additional services } \\
\text { (Russian, cunnilingus ...) } \\
\text { apart from vaginal } \\
\text { penetration, anal penetration } \\
\text { (prostitute or client), fellatio } \\
\text { and SM. }\end{array}$ & $\begin{array}{l}\text { Reviewers indicate which } \\
\text { services they have used from } \\
\text { a list of } 26 \text { possible additional } \\
\text { services. }\end{array}$ \\
\hline Country: Belgium & $\begin{array}{l}\text { Country where the interaction } \\
\text { took place }(0 \text { : The Netherlands, } \\
\text { 1: Belgium) }\end{array}$ & $\begin{array}{l}\text { The reviews are classified in } \\
\text { segments, as a combination } \\
\text { of the type of prostitution and } \\
\text { the location (for example, } \\
\text { windows and street } \\
\text { prostitution in Amsterdam). }\end{array}$ \\
\hline
\end{tabular}


Table 2 (Continued)

Variables used in the regression model

Indigenous

Dark skin

Eastern
Explanation

Belgian or Dutch prostitute

(0:No, 1:Yes)

South European, Surinamese, African or Latina prostitute (0:No, 1:Yes)

Thai, Chinese or other Asian prostitute (0:No, 1:Yes)

Streetwalking, brothels and clubs, massage parlour, gangbangs and SM, escort and private, transsexuals Contract fulfilled
Dummy variables for each prostitution segment (reference category is windows prostitution) Dummy variable
Based on the following topics in the standardised questionnaire

\author{
Item about the ethnic \\ background chosen from a list \\ of 12 ethnic or national groups \\ (Dutch, Belgian, German, \\ south European, east European, \\ Surinamese, African, Thai, \\ Chinese, other Asian, Latina, \\ elsewhere or 'don't know'). \\ Based on the (level 3) \\ classification in segments \\ (see Country: Belgium)
}

Yes or no question in the questionnaire

Note: SM, sado-masochism.

prostitution is reduced mainly through the use of condoms. Research consistently shows a decline in infections when the use of condoms rises (for example Ward et al. 2004).

If a client and a sex worker have sexual intercourse without protective measures, the highest risk of infection lies in types of intercourse with penetration. Unprotected anal intercourse carried the highest overall risk of infection. Vaginal intercourse usually has high infection risks also, both for the penile and the vaginal partner. Though oral sex in general is less infectious - the evidence of possible HIV transmission through oral sex, for example, is inconclusive (Campo et al. 2006) - this should not lead to the conclusion that unprotected oral sex is low-risk behaviour. Quite the contrary. Other STDs are easily transmitted through oral sex (Edwards and Carne 1998a, 1998b). The evidence, for instance, suggests a rising incidence of oral infection with syphilis (Ciesielski et al. 2004). Prophylaxis in oral intercourse is less documented and public health organisations seem to pay less attention to the prevention of infections through oral sex. Protective measures such as condoms or dental dams, nevertheless, provide effective protection.

From the point of view of unsafe sexual behaviour our dataset documents three relevant categories where the reviewer explicitly denotes whether a condom was used: fellatio and vaginal and anal penetration of the sex worker. Therefore, we focus on these types of unsafe sexual behaviour and omit those where the data do not allow us to distinguish between unsafe and protected behaviour, that is, intercourse where the client is the oral partner (cunnilingus and oro-anal contact). In short, we consider an interaction as unsafe when at least one of the following services took place without a protective sheath: vaginal penetration, anal penetration or fellatio.

Using this measure, one in four acts of intercourse $(23.9 \%)$ can be regarded as unsafe. From the perspective of the sex workers, almost one-third $(31 \%)$ have had at least one recorded form of intercourse considered to be unsafe. The biggest source of unsafe sexual practices is unprotected fellatio (in 29.6 per cent of the interactions). The lowest prevalence of unsafe practices is found in vaginal intercourse, where only 1.9 per cent of vaginal 
penetrations take place without a condom. Surprisingly the picture is different in the quite infectious case of unprotected anal penetration. More than one in ten $(10.2 \%)$ of the encounters are reported to take place without a condom. This type of practice, however, is rather exceptional: only in the case of one in ten sex workers and one in twenty interactions is anal penetration reported.

The question is how these unsafe sexual practices are distributed throughout the group of sex workers and throughout the different segments of the prostitution market. Indeed, the literature shows that unsafe sexual practices are concentrated within some distinct clusters in the prostitution market. Classical examples are streetwalkers, brothels and escort services. Most of the literature assumes that these segments are stratified, namely, that they are ordered from low to high, with streetwalkers in the former and escort services in the latter end. Because of their ordered structure, the market segments can also be called strata.

Women working outdoors and illegal prostitutes have lower scores on safety, working conditions and mental and physical health (Raphael and Shapiro 2004). This is consistent with prophylactic use, which is less systematically used by women working outdoors (Minh et al. 2004) and those servicing clients outdoors (Shannon et al. 2009). Most of the literature assumes that these findings are reflections of the ordering of market segments measured by price and safe practices: escort services rank highest, then come clubs and brothels, and windows and street prostitution are at the bottom of prostitution markets (for example, Van den Hazel et al. 2008, Weitzer 2010). In our data this hierarchy is replicated for the prices paid. It may apply to other unmeasured elements of occupational quality but the prevalence of unsafe sexual practices is not only no higher in the lower strata, quite the opposite is the case: the prevalence of unsafe practices is proportional to the market segment (ordinal measure of association $\gamma$ equals $0.610, \chi^{2}=935.0944505, P$-value $\left.<0.0001\right)$.

Older sex workers engage in unprotected intercourse far more often $(\gamma=0.225)$. The same applies to the rated attractiveness: the more that clients perceive sex workers as unattractive, the higher the odds are that they engage in unsafe sexual practices $(\gamma=-0.156)$.

The overall picture is that unsafe sexual practices are a persistent part of commercial sexual transactions. They are also associated with the market segment and with some of the characteristics of an individual sex worker. Some correlates suggest that sex workers in a weaker position, for instance those who are older and less attractive, are more often pushed towards unsafe sexual contacts. On the other hand there is a remarkably positive association between the status of prostitution segments and the prevalence of unsafe sexual contacts. The overall question ensuing from these findings is whether one can make sense of the sexual behaviour of sex workers. This is the central problem tackled in the next sections.

\section{Explaining unsafe sex: the health risk differential}

As is shown above, a significant part of the sexual intercourse taking place in prostitution is unsafe. In order to unveil the logic behind this persistence of unsafe sexual practices we will reconstruct the reasons behind them. Such an explanation may also suggest ways of altering sexual practices.

Some have attempted to make sense of prostitution by economic theorising (for example, Baumeister and Vohs 2004, Edlund and Korn 2002). These theoretical attempts, however, often suffer from a lack of empirical acquaintance with the world of sex workers and from assumptions that may be consistent but not realistic. A striking example is Edlund and Korn's (2002) assertion that the cost of being a prostitute consists of chances lost on the 
marriage market (convincingly falsified in Arunachalam and Shah 2008 and shown to be improbable in Peracca et al. 1998).

At the same time a handful of economists have contributed in the past decade to the prostitution debate in quite a revealing manner. Some have suggested promising and empirically informed approaches (for example, Cameron 2002, Reynolds 1986). Others successfully combine data with theoretical economic insights (Della Giusta et al. 2009, Gertler et al. 2005, Moffatt and Peters 2004, Rao et al. 2003).

Table 3: Summary statistics for the variables used in the tested models

\begin{tabular}{|c|c|c|c|c|}
\hline & $\begin{array}{l}\text { Multilevel } \\
\text { model }\end{array}$ & $\begin{array}{l}\text { Fixed-effects } \\
\text { model }\end{array}$ & $\begin{array}{l}\text { Fixed-effects } \\
\text { model on } \\
\text { sample }\end{array}$ & $\begin{array}{l}\text { Multilevel } \\
\text { ordinal } \\
\text { regression } \\
\text { (see Table 5) }\end{array}$ \\
\hline \multicolumn{5}{|l|}{ Level 1: transactions } \\
\hline Count & 23,322 & 24,277 & 8,408 & 20,979 \\
\hline Transaction price $(€)$ & $88.67(73.76)$ & $89.11(73.68)$ & $98.76(73.99)$ & $87.56(73.91)$ \\
\hline Logarithm of price & $4.29(0.595)$ & $4.29(0.596)$ & $4.40(0.598)$ & $4.27(0.599)$ \\
\hline Unsafe sexual practices $(\%)$ & 24.1 & 24.0 & 48.4 & 27.7 \\
\hline Duration (min.) & $43.10(35.60)$ & $43.47(36.12)$ & $50.58(37.42)$ & $41.92(35.41)$ \\
\hline Logarithm of duration & $3.55(0.629)$ & $3.55(0.634)$ & $3.74(0.597)$ & $3.52(0.623)$ \\
\hline Appearance rating ( 1 to 5 ) & $4.04(0.902)$ & $4.04(0.907)$ & $3.92(0.924)$ & $4.05(0.897)$ \\
\hline Anal (prostitute) $(\%)$ & 5.0 & 5.1 & 8.3 & \\
\hline Anal (client) $(\%)$ & 4.0 & 4.1 & 4.8 & \\
\hline SM $(\%)$ & 1.2 & 1.2 & 0.50 & \\
\hline Total of extra services & $1.01(1.68)$ & $1.01(1.69)$ & $0.450(0.498)$ & $1.05(1.706)$ \\
\hline Hygiene rating ( 1 to 5 ) & & & & $4.26(0.888)$ \\
\hline Contract carried out $(\%)$ & & & & 94.6 \\
\hline \multicolumn{5}{|l|}{ Level 2: sex workers (\%) } \\
\hline Count & 6,638 & 7,340 & 1,148 & 6,237 \\
\hline Age & $29.14(7.47)$ & & & $29.07(7.48)$ \\
\hline Thin $(\%)$ & 3.8 & & & 3.8 \\
\hline Obese $(\%)$ & 14.3 & & & 14.4 \\
\hline Country: Belgium (\%) & 24.0 & & & \\
\hline Autochthon (\%) & 35.5 & & & 35.4 \\
\hline Dark skin $(\%)$ & 17.1 & & & 17.3 \\
\hline Eastern $(\%)$ & 7.9 & & & 6.5 \\
\hline Streetwalking (\%) & 1.5 & & & 1.5 \\
\hline Windows $(\%)$ & 43.1 & & & 45.0 \\
\hline Brothels and clubs $(\%)$ & 19.0 & & & 19.5 \\
\hline Massage parlour (\%) & 6.0 & & & 3.4 \\
\hline Gangbangs and SM (\%) & 2.0 & & & 1.9 \\
\hline Escort and private $(\%)$ & 26.2 & & & 26.2 \\
\hline Transsexuals (\%) & 2.3 & & & 2.4 \\
\hline \multicolumn{5}{|l|}{ Level 3: segment } \\
\hline Count & 50 & & & 50 \\
\hline
\end{tabular}

Note: For quantitative variables the means and standard deviations (in parentheses) are reported. For qualitative variables, percentages are reported.

SM, sado-masochism.

(C) 2011 The Authors

Sociology of Health \& Illness (c) 2011 Foundation for the Sociology of Health \& Illness/Blackwell Publishing Ltd 
Some have as a result applied the hedonic pricing method developed by Sherwin Rosen (1974) to the prostitution market. The method deals with markets where products can be deliberately differentiated. In these cases a certain demand, for example, for unprotected sexual intercourse, combined with a preference of suppliers against condom use, will have an impact on the price of transactions. The underlying idea is that a service that is wanted by clients, but bears certain health risks for sex workers will only be supplied at a higher price. Sex workers are thus compensated for the increased risk by a higher income. The mechanism of equalising differences thus creates a negative relationship between condom use and the price charged. This so-called compensating differential is confirmed in studies by Rao (2003) in Calcutta and Gertler (2005) in Mexico. They estimate that premiums for unsafe sex vary between 23 and 79 per cent. The wage penalty of safe sex is so high for sex workers that they have the choice between extreme income cuts and unsafe sexual practices.

In this section we replicate the previous hedonic pricing analyses. Using this method we aim at testing the hypothesis that a price incentive for unprotected sex also exists in the prostitution markets of Belgium and The Netherlands. The primary function of this is to estimate whether the net price incentive for unsafe sexual practices is strong enough to rationalise their persistence. If this is the case, income might provide a consistent pressure on sex workers not to use a condom. Table 3 summarises some descriptive statistics for the variables used in the three estimated models, as well as for the model estimated in the next section.

The data have a particular and quite complicated multilevel structure with at least three hierarchical levels: the localised segment, the sex worker involved and the concrete interaction reported. Two appropriate techniques are available to deal with these data: multilevel analysis and fixed-effects modelling. We propose both analyses in Table 4.

The dependent variable is the natural logarithm of the price. Using a condom is a variable measured at the level of an encounter between a sex worker and her client: this variable is indicated as unsafe sexual practice.

The first model presented is the multilevel analysis. Condom use is at the lowest level of measurement in our data structure (level 1). At this level other relevant information is the duration of the encounter, the appearance rated by the client and the services provided. Level 2 consists of the characteristics of the sex worker: age, ethnic background and shape. The final level (level 3) refers to the localised market segment. In the fixed parameters we distinguished between streetwalkers, windows prostitution, clubs and brothels, massage

Table 4 Fixed and random-effects estimates (standard error) of the price logarithm

\begin{tabular}{lrll}
\hline & Multilevel model & Fixed-effects model & Fixed-effects model on sample \\
\hline Intercept & $2.405^{* *}(0.092)$ & $2.247^{* *}(0.037)$ & $2.287^{* *}(0.062)$ \\
Unsafe sexual practices & $0.037^{*}(0.016)$ & $0.063^{* *}(0.009)$ & $0.068^{* *}(0.009)$ \\
Duration (ln) & $0.566^{* *}(0.024)$ & $0.559^{* *}(0.010)$ & $0.547^{* *}(0.016)$ \\
Age & $-0.010^{* *}(0.00)$ & & \\
Thin (prostitute) & $-0.004(0.017)$ & & \\
Obese (prostitute) & $-0.050^{* *}(0.01)$ & & \\
Appearance rating & $0.008^{* *}(0.002)$ & $0.001(0.003)$ & $0.001(0.005)$ \\
Anal (prostitute) & $0.093^{* *}(0.009)$ & $0.084^{* *}(0.016)$ & $0.068^{* *}(0.019)$ \\
Anal (client) & $0.094^{* *}(0.010)$ & $0.084^{* *}(0.013)$ & $0.063^{* *}(0.018)$ \\
SM & $0.105^{* *}(0.019)$ & $0.123^{* *}(0.031)$ & $0.123^{*}(0.054)$ \\
Total of extra services & $0.022^{* *}(0.002)$ & $0.024^{* *}(0.002)$ & $0.016^{* *}(0.003)$ \\
\hline
\end{tabular}

Note: $* P \leq 0.05, * * P \leq 0.01$. 
Table 5 Fixed-effects estimates (standard error) of client satisfaction

Fixed-effects parameters

Unsafe sexual practices

Constant 1

Constant2

Contant3

Constant4

Price (ln)

Duration (ln)

Age

Thin (prostitute)

Obese (prostitute)

Appearance rating

Hygiene rating

Contract fulfilled

Number of services

Country: Belgium

Autochthon (prostitute)

Dark skin (prostitute)

Eastern (prostitute)

Type: streetwalking ${ }^{\dagger}$

Type: brothels and clubs ${ }^{\dagger}$

Type: massage parlours ${ }^{\dagger}$

Type: gangbangs and $\mathrm{SM}^{\dagger}$

Type: escort and private ${ }^{\dagger}$

Type: transsexuals ${ }^{\dagger}$

$$
\begin{array}{r}
0.475 * *(0.033) \\
3.655^{* *}(0.158) \\
4.574 * *(0.157) \\
5.553 * *(0.158) \\
7.162 * *(0.161) \\
-0.291 * *(0.037) \\
0.755 * *(0.035) \\
0.009 * *(0.002) \\
-0.021(0.073) \\
-0.013(0.042) \\
0.469 * *(0.015) \\
0.577 * *(0.014) \\
1.544 * *(0.044) \\
0.078 * *(0.010) \\
-0.081(0.073) \\
0.127 * *(0.038) \\
0.007(0.044) \\
0.049(0.069) \\
-0.283 *(0.132) \\
-0.351 * *(0.075) \\
-0.924 * *(0.164) \\
-0.502 * *(0.149) \\
-0.510^{* *}(0.092) \\
-0.082(0.150)
\end{array}
$$

Note: $* P \leq 0.05, * * P \leq 0.01$.

${ }^{\dagger}$ Windows prostitution served as the reference category.

The random-effects variances and level-2 variables were not reported. Multilevel models were estimated with the help of the software package MLWin; fixed-effect models with Stata.

SM, sado-masochism.

parlours, escort and private encounters, transsexuals and finally bondage and discipline, dominance and submission (BDSM) and gangbangs. In these parameters a dummy of the country was introduced (Belgium versus The Netherlands). A more detailed reference to the prostitution segment is reflected in the third level of the random effects. This refers to a certain type of prostitution in a city or region. For instance, in this manner brothel prostitution was distinguished from one city to another.

In Table 4 three models are presented. The first column presents a multilevel or randomeffects model. We used random slopes for (the logarithm of) the duration and unsafe sexual practice, both at level 2 and 3, and included possible correlations between the different random slopes and the random intercept at each level. This allows for the unsafe sex price premium to vary according to the actual sex worker and the market segment. A restricted maximum likelihood estimation was used to estimate the coefficients of the multilevel model. Because levels 2 and 3 are not central to our model they are not presented in Table 4.

The Hausman test confirmed that the fixed-effects and the random-effects estimates differ significantly. This suggests that the idiosyncratic error term is correlated to the independent variables. The random-effects estimates probably are biased. Therefore a fixed-effects model is more appropriate. These are represented in the second and third models. The second 
column shows the results of the fixed-effects regression. The third and final column excludes sex workers who always or never use condoms. Indeed, one possible problem is that we lack data for both unsafe and safe sexual interactions for a considerable proportion of the sex workers. There are two reasons for this. On the one hand, it is probable that a considerable proportion of the sex workers always practise safe sex. On the other hand, in the case of sex workers with a small sample of reported transactions, the chances are high that the lack of sufficient reviews is the cause of the absence of reported unsafe sexual practices. Therefore, an analysis of all the reviews may not allow us to isolate the effect of condom use on the price properly. We thus replicated the fixed-effects analysis on those sex workers for whom interactions were reported with and without a condom. These arguments lead us to the expectation that the third model is the final one.

First of all, a null model (or intercept only model) was estimated, with a fixed-intercept and random intercepts at level 2 and 3 (not reported in Table 4). This model checks whether there is price variation between the sex workers, the location and the market segment. From this null model we infer that the residual variability (level 1 variance) is 0.128 , the variability between prostitutes (level 2 variance) is 0.085 and the variability between segments (level 3 variance) is 0.140 . All together this comes to a total variability of 0.353 . This means that the intraclass correlation (between two interactions of the same prostitute in the same segment) is $(0.085+0.140) / 0.353=63.7$ per cent. In other words, almost two-thirds of the total variability in the (logarithm of the) price is due to variability between prostitutes and between segments. These estimates confirm that a multilevel analysis was appropriate.

The multilevel model (the first column of Table 4) shows that unsafe sexual practices have a significant effect on the (logarithm of the) price, under the control of other relevant variables. The significance of the effect is a little above 1 per cent. This is also reflected in the moderate estimated effect of unsafe sexual practices on the price.

The most striking result of the fixed-effects estimate in the second column is that unsafe sexual practices have a much stronger estimated effect here on the (logarithm of the) price of the interaction.

If we count back from the logarithmic dependent variable to the original price, a coefficient of 0.063 means that there is an estimated price premium of 6.5 per cent for unsafe sex. This effect is considerable but it is definitely smaller than the effects estimated in the research by Rao (2003) and Gertler et al. (2005). One possible explanation may lie in the differences in attitude towards unprotected intercourse from clients in Mexico and Calcutta in comparison to clients in The Netherlands and Belgium. The role of preferences is analysed in the next section.

The third model confirms the former results, but the effect of unsafe sexual practices becomes even stronger. The net effect of unsafe sex increases to 7.2 per cent in the final estimate. As mentioned earlier, we argue that the third model gives the most precise estimate of the compensating differential for unsafe sex. To sum up, a compensating differential of unsafe sexual practices, previously found in studies in Mexico and India, is also at work in the prostitution markets of Belgium and The Netherlands. However, the level of the premium does seem to be lower.

\section{Explaining unsafe sex: clients' preferences}

The hedonic pricing method has provided us with one account for why sex workers give in to the demand for unsafe sex. The price motivator does seem to be effective for the prostitution markets of the Low Countries. As shown, the premium for unsafe sex is estimated to be 
higher in Mexico and Calcutta. How can we account for these differences in outcome? One of the possible explanations may be attributed hypothetically to the differences in the overall preference of clients for unprotected sex, or in the willingness of sex workers in Calcutta, Mexico and the Low Countries to give up the condom.

Indeed, the emphasis on price incentives as the sole motivator for unsafe sexual practices has met with some explicit resistance. There is a recurring sociological critique on the neoclassical economic standpoint that price captures people's information and preferences and therefore serves as a perfect and complete coordination mechanism for social actions. This critique can be easily applied to the field of unsafe sexual practices in prostitution. Far from questioning the relevance of price incentives, it is arguable that it does not cover the complete set of people's concerns and goals. Other reasons for deciding to use condoms or use unprotected sex exist, possibly together with the price mechanism. Some researchers (for example, Brewis and Linstead 2000, Sanders 2005) argue that health and safety is but one reason for using a condom. In interviews sex workers often stress that a condom also provides a symbolic distance between themselves and their private lives on the one hand and the client on the other (see also Jackson et al. 2005), thus providing the so eagerly wanted lack of intimacy. The existence of this symbolic boundary between sex work and intimate life might ground the expectation that (some) prostitutes always decline unprotected intercourse.

Concurrently, alternative motivations that provide reasons for unprotected sex also exist. Not using a condom is not only inspired by price incentives but may be inspired by other motivations, for example, for fear of violent reactions by clients. This has recently been documented in a prostitution study in Managua (Nicaragua) (Willman 2008) and is supported by other research, both quantitative (Shannon et al. 2009) and qualitative (Busza 2005). The evidence thus suggests the existence of a different kind of compensating differential: in some instances sex workers have the choice between getting a beating with a condom and getting out in one piece at the cost of having unprotected sex. Willman's research points out that this 'choice' also may go together with significant price incentives.

In sum, there is a set of valid and consistent critiques that the importance of price in decisions about safe sex is overrated. In order to test them, however, two approaches are feasible. Firstly, one can measure them directly with the parties involved. Though this would be an interesting approach, our data do not allow us to document the motivations of sex workers directly. An alternative approach exists of direct analysis of the ground for the whole discussion about condom use: the assumed preference of clients for unprotected sex. What the hedonic regression approach has in common with its critiques is the assumption that at least a significant part of the clients prefer unsafe sexual services. Based upon the comments from reviewers on the user-generated websites, this can only be confirmed. Therefore we aim at testing this on a standardised dataset.

To be clear: this assumed preference has effects only when sex workers actually give in to it, whether for price incentives or for other reasons. It would be precisely because a proportion of male clients prefer it that the procurement of unsafe sexual practices could be used as a commercial strategy by sex workers. A consistent demand for unsafe sex due to this preference is therefore logically prior to its actual persistence.

We argue that an estimate of the net effect of clients' satisfaction may serve as a proxy of their taste for unprotected sexual intercourse. If clients are more satisfied with unsafe sexual practices under the control of other important features of the sex workers and the service provided, this would be consistent with the idea of a strong preference for unprotected sexual practices on the part of clients.

Clients can give an appreciation of the interaction on a five-point scale ranging from poor (1) to excellent (5). They can do so for the services vaginal penetration, fellatio, anal 
penetration by the client and the reverse, and for sado-masochism (SM). The website calculates the average of the reported ratings, rounded to an integer, and reports this as a general appreciation. We use this rounded average rating as our dependent variable. Because this variable has an ordinal measurement level, a multilevel ordinal regression was performed (Agresti and Natarajan 2001, Hedeker 2008). Many clients report a higher level of satisfaction. For a distribution that is left skewed, the appropriate ordinal analysis makes use of a complementary log-log function. Unfortunately we cannot compare this multilevel regression with unconditional fixed-effects estimates because of the risk of inconsistency. The literature clearly indicates that unconditional fixed-estimates of within-prostitutes effects would be biased (Ferrer-i-Carbonell and Frijters 2004: 131, Rabe-Hesketh and Skrondal 2003: 648).

The analysis (Table 5) indeed confirms that unsafe sexual practices have a strong effect on client satisfaction. The control of important background variables such as age, duration of the transaction, price and segment are most often appropriate, as they have significant effects on satisfaction themselves but do not wipe out the weight of the effect of unsafe sexual practices. In other words, using a condom does diminish clients' satisfaction about the encounter with a sex worker, thereby confirming their general preference for unsafe sexual practices.

\section{Conclusions and discussion}

This article deals with possible infection risks of male clients and female sex workers in prostitution. Unsafe sexual practices that heighten the infection risk are equated to not using a condom during commercial sexual services. The article aims to explain the persistence of unsafe sexual practices in prostitution. For this purpose a dataset was collected of almost 25,000 reports from a user-generated website representing the main segments of the prostitution markets in the Low Countries.

The use of condoms provides an acceptable protection against infection with STDs in commercial sexual encounters. Sexual encounters are therefore unsafe when no condom is used in fellatio, vaginal or anal intercourse. The data show that the prevalence of unsafe sexual practices is concentrated in oral intercourse but occurs in vaginal and anal intercourse also. All in all, almost one in three sex workers $(31 \%)$ has had at least one recorded unsafe interaction, and one in four of the encounters can be considered unsafe $(23.9 \%)$. Unsafe sexual practices occur more often with older sex workers and when the clients perceive the sex worker as unattractive. The prevalence of unsafe practices is higher in those segments of the prostitution market that are more prestigious and costly, such as escort services.

A first analysis of the persistence of unsafe sexual practices replicates the hedonic pricing method hypothesising that the higher price for unprotected intercourse explains the persistence of unsafe sexual practices. The logic behind this approach is that higher wages provide a rational incentive for sex workers to give in to the demand for unsafe interaction. This mechanism has recently been tested and confirmed in prostitution markets in Calcutta, Mexico and Managua. The replication in our data supports the existence of this mechanism in the sex markets of the Low Countries. However, the estimated premium for unsafe interaction is lower in the Low Countries than in Mexico and Calcutta. A possible reason for this difference may lie in differences in the preference of clients for unprotected intercourse.

The second part of the analysis starts from the objections against income as the sole motivator for unsafe sex. For instance, fear of violence by clients has been cited as an alternative motivation. Both the hedonic pricing method and its critiques assume that the 
preference for unprotected sexual intercourse lies at the basis of its persistence. Whatever the actual incentive may be, the underlying source of unsafe practices would be the clients' preference for it. This logic was tested on our data with the help of an ordinal multilevel regression. The analysis confirms the hypothesis that, net of other effects, a client who has had unprotected intercourse will be more satisfied.

What can we learn from these analyses for the purpose of policy? The most important conclusion is that a public health policy solely aiming at sex workers as the prime target group negates a major risk factor behind the spread of STDs: the clients' preferences (compare Plumridge et al. 1997). The evidence suggests that the persistence of unsafe sexual practices is primarily an effect of the consistent inclination of clients. Therefore the shortest way to effective prevention is to address this group more intensively.

Address for correspondence: Stef Adriaenssens, Hogeschool-Universiteit Brussel (University College Brussels) Human Relations Research Group, Warmoesberg 26, Brussels 1000, Belgium

e-mail: stef.adriaenssens@hubrussel.be

\section{Acknowledgements}

The authors thank Dieter Verhaest for his most constructive criticisms, Johan Eyckmans for his creative suggestions and the anonymous referees for their comments. We are also obliged to Loes Tweepenninckx and Lydie Verschueren for their excellent support in the data collection.

\section{Notes}

1 Prostitution and sex work are used as synonyms, and likewise prostitute and sex worker.

2 The website is managed by a firm that commercialises the project through advertisements. Content and use of the website are free, however.

\section{References}

Agresti, A. and Natarajan, R. (2001) Modeling clustered ordered categorical data: a survey, International Statistical Review, 69, 3, 345-71.

Aral, S.O. (2004) Sexual risk behaviour and infection: epidemiological considerations, Sexually Transmitted Infections, 80, Suppl. 2, ii8-ii12.

Arunachalam, R. and Shah, M. (2008) Prostitutes and brides? American Economic Review, 98, 2, 516-22.

Baumeister, R.F. and Vohs, K.D. (2004) Sexual economics: sex as female resource for social exchange in heterosexual interactions, Personality and Social Psychology Review, 8, 4, 33963.

Blevins, K.R. and Holt, T.J. (2009) Examining the virtual subculture of johns, Journal of Contemporary Ethnography, 38, 5, 619-48.

Brewis, J. and Linstead, S. (2000) The worst part is the screwing (1): consumption and the management of identity in sex work, Gender, Work \& Organization, 7, 2, 84-97.

Busza, J. (2005) How does a 'risk group' perceive risk? Voices of Vietnamese sex workers in Cambodia. In Parsons, J.T. (ed.) Contemporary Research on Sex Work. Binghamton: Haworth Press. 
Cameron, S. (2002) The Economics of Sin: Rational Choice or No Choice at All? Cheltenham: Edward Elgar.

Campo, J., Perea, M.A., del Romero, J., Cano, J, et al. (2006) Oral transmission of HIV, reality or fiction? An update, Oral Diseases, 12, 3, 219-28.

Chacham, A.S., Diniz, S.G., Maia, M.B., Galati, A.F., et al. (2007) Sexual and reproductive health needs of sex workers: two feminist projects in Brazil, Reproductive Health Matters, 15, 29, 10818.

Ciesielski, C., Tabidze, I. and Brown, C. (2004) Transmission of primary and secondary syphilis by oral sex - Chicago, Illinois, 1998-2002, Morbidity and Mortality Weekly Report, 292, 20, 245961.

Cusick, L. (2006) Widening the harm reduction agenda: from drug use to sex work, International Journal of Drug Policy, 17, 1, 3-11.

Cwikel, J., Ilan, K. and Chudakov, B. (2003) Women brothel workers and occupational health risks, Journal of Epidemiology and Community Health, 57, 10, 809-15.

Della Giusta, M., Di Tommaso, M.L., Shima, I. and Strøm, S. (2009) What money buys: clients of street sex workers in the US, Applied Economics, 41, 18, 2261-77.

Döring, N.M. (2009) The Internet's impact on sexuality: a critical review of 15 years of research, Computers in Human Behavior, 25, 5, 1089-101.

Edlund, L. and Korn, E. (2002) A theory of prostitution, Journal of Political Economy, 110, 1, $181-214$.

Edwards, S. and Carne, C. (1998a) Oral sex and the transmission of non-viral STIs, Sexually Transmitted Infections, 74, 2, 95-100.

Edwards, S. and Carne, C. (1998b) Oral sex and the transmission of viral STIs, Sexually Transmitted Infections, 74, 1, 6-10.

Farley, M., Baral, I., Kiremire, M. and Sezgin, U. (1998) Prostitution in five countries: violence and post-traumatic stress disorder, Feminism and Psychology, 8, 4, 405-26.

Ferrer-i-Carbonell, A. and Frijters, P. (2004) How important is methodology for the estimates of the determinants of happiness? The Economic Journal, 114, 497, 641-59.

Gertler, P., Shah, M. and Bertozzi, S.M. (2005) Risky business: the market for unprotected commercial sex, Journal of Political Economy, 113, 3, 518-50.

Hedeker, D. (2008) Multilevel models for ordinal and nominal variables. In de Leeuw, J. and Meijer, E. (eds) Handbook of Multilevel Analysis. New York: Springer.

Holroyd, E.A., Wong, W.C.W. and Ling, D.C. (2008) Environmental health and safety of Chinese sex workers: a cross-sectional study, International Journal of Nursing Studies, 45, 1, 932-41.

Hookers (n.d.) Home page. Available at www.hookers.nl (last accessed 10 August 2011).

Hubbard, P. (2004) Cleansing the metropolis: sex work and the politics of zero tolerance, Urban Studies, 41, 9, 1687-702.

Jackson, L.A., Sowinski, B., Bennett, C. and Ryan, D. (2005) Female sex trade workers, condoms and the public-private divide. In Parsons, J.T. (ed.) Contemporary Research on Sex Work. Binghamton: Haworth Press.

Kantola, J. and Squires, J. (2004) Discourses surrounding prostitution policies in the UK, European Journal of Women's Studies, 11, 1, 77-101.

Korn, M. (2008) Sexually transmitted diseases. In Kirch, W. (ed.) Encyclopedia of Public Health. New York: Springer.

Minh, T.T., Nhan, D.T., West, G.R., Durant, T.M., et al. (2004) Sex workers in Vietnam: how many, how risky? Aids Education and Prevention, 16, 5, 389-404.

Moffatt, P.G. and Peters, S.A. (2004) Pricing personal services: an empirical study of earnings in the UK prostitution industry, Scottish Journal of Political Economy, 51, 5, 675-90.

Murphy, A.K. and Venkatesh, S.A. (2006) Vice careers: the changing contours of sex work in New York City, Qualitative Sociology, 29, 2, 129-54.

Peracca, S., Knodel, J. and Saengtienchai, C. (1998) Can prostitutes marry? Thai attitudes toward female sex workers, Social Science and Medicine, 47, 2, 255-67. 
Plumridge, E.W., Chetwynd, S.J. and Reed, A. (1997) Control and condoms in commercial sex: client perspectives, Sociology of Health and Illness, 19, 2, 228-43.

Punternet (n.d.) Why field reports are rejected. Available at http://www.punternet.com/frs/ fr_reject.html (last accessed 10 August 2011).

Quinn, J.F. and Forsyth, C.J. (2005) Describing sexual behavior in the era of the Internet: a typology for empirical research, Deviant Behavior, 26, 3, 191-207.

Rabe-Hesketh, S. and Skrondal, A. (2003) Multilevel and Longitudinal Modeling Using Stata, College Station: Stata Press.

Rao, V., Gupta, I., Lokshin, M. and Jana, S. (2003) Sex workers and the cost of safe sex. The compensating differential for condom use in Calcutta, Journal of Development Economics, 71, 2, 585-603.

Raphael, J. and Shapiro, D.L. (2004) Violence in indoor and outdoor prostitution venues, Violence against Women, 10, 2, 126-39.

Reynolds, H. (1986) The Economics of Prostitution, Springfield: Charles C. Thomas.

Rosen, S. (1974) Hedonic prices and implicit markets: product differentiation in pure competition, Journal of Political Economy, 82, 1, 34-55.

Sanders, T. (2004) A continuum of risk? The management of health, physical and emotional risks by female sex workers, Sociology of Health and Illness, 26, 5, 557-74.

Sanders, T. (2005) It's just acting: sex workers strategies for capitalizing on sexuality, Gender, Work \& Organization, 12, 4, 319-42.

Shannon, K., Strathdee, S.A., Shoveller, J., Rusch, M., Kerr, T. and Tyndall, M.W. (2009) Structural and environmental barriers to condom use negotiation with clients among female sex workers: implications for HIV-prevention strategies and policy, American Journal of Public Health, 99, 4, 659-65.

Simić, M. and Rhodes, T. (2009) Violence, dignity and HIV vulnerability: street sex work in Serbia, Sociology of Health and Illness, 31, 1, 1-16.

Soothill, K. and Sanders, T. (2005) The geographical mobility, preferences and pleasures of prolific punters: a demonstration study of the activities of prostitutes clients, Sociological Research Online, 10, 1.

Van den Hazel, R., Lesger, D., Peters, T., Van Oijen, S., Loopmans, M., Gabiam, K. and Kesteloot, C. (2008) Prostitutie Brussel in beeld. Bouwstenen voor een integraal beleid, Arnhem: Seinpost Adviesbureau.

Ward, H., Day, S., Green, A., Cooper, H., et al. (2004) Declining prevalence of STI in the London sex industry, 1985 to 2002, Sexually Transmitted Infections, 80, 374-78.

Weitzer, R. (2010) Sex work: paradigms and policies. In Weitzer, R. (ed.) Sex for Sale. Prostitution, Pornography, and the Sex Industry. New York: Routledge.

Willman, A. (2008) Safety first, then condoms: commercial sex, risky behavior, and the spread of HIV/AIDS in Managua, Nicaragua, Feminist Economics, 14, 4, 37-65.

Wong, W.C.W., Holroyd, E.A., Gray, A. and Ling, D.C. (2006) Female street sex workers in Hong Kong: moving beyond sexual health, Journal of Women's Health, 15, 4, 390-99. 